\title{
ESCRITA FEMININA E DISCURSO: \\ A DESCOBERTA DE UM SUJEITO EM RACHEL DE QUEIROZ E HELEUSA CÂMARA
}

RESUMO: O presente trabalho propõe ler e analisar a escrita e o discurso feminino nas escritoras nordestinas Rachel de Queiroz e Heleusa Câmara, a fim de problematizar a descoberta e construção do sujeito feminino. Como objeto de estudo tem-se o primeiro romance de Rachel de Queiroz, $O$ quinže, publicado pela primeira vez em 1930, e a coletânea de contos de Heleusa Câmara, Mulheres acorrentadas, de 1982, na qual analisar-se-á, especificamente, os contos Joana da cata-nica e As lutas de Loura. O objetivo é problematizar, através da observância das narrativas, como é realizada a construção do sujeito feminino por cada autora, além de questionar a noção de "sujeito universal". Dessa forma, observa-se a relevância do trabalho, que busca perceber, de acordo com a visão de um elemento que muitas vezes foi deixado de fora da história, a noção da construção de protagonismo de sujeito marginalizado feminino. Como metodologia, sustentamo-nos na Análise Crítica do Discurso (ADC), proposta por Teun A. van Dijk (2010), para, além de apontar os discursos narrativos das autoras e suas protagonistas, também analisar, em uma perspectiva crítica-feminista, como ocorre a construção desses sujeitos.

PALAVRAS-CHAVE: Discurso; Heleusa Câmara; Mulher; Rachel de Queiroz; Sujeito.

\footnotetext{
* Mestranda em Letras: Cultura, Educação e Linguagens, pela Universidade Estadual do Sudoeste da Bahia.

** Doutora em Semiologia pela Universidade Federal do Rio de Janeiro (UFRJ). Realizou estágio de Pós-doutorado no Programa de Pós-graduação em Letras da Universidade Federal de Pernambuco (UFPE). Professora Titular da Universidade Estadual do Sudoeste da Bahia (Uesb).
} 


\section{Introdução}

Joan Scott (1992), quando discute a respeito da importância de fala e lugar concedidos às mulheres ao longo da história, problematiza a respeito de uma exclusão feminina baseada em um pseudoprincípio de universalidade, ditada pelo padrão de sujeitos que protagonizavam a produção de discursos acadêmicos, filosóficos, sociais e até mesmo morais, sendo caracterizados como uma maioria de homens brancos, heteronormativos e de classe econômica abastada. Devido ao fato desse grupo contar a história de acordo com sua perspectiva, outros ficavam de fora até mesmo do que seria considerado como sujeito, sendo assim, não protagonizaram a construção da historiografia, tendo como consequência o silenciamento de suas versões. Para Scott,

A historiografia das mulheres, sugerindo que ela faz uma modificação da "história", investiga o modo como o significado daquele termo geral foi estabelecido. Questiona a prioridade relativa dada à "história do homem", em oposição à "história da mulher", expondo a hierarquia implícita em muitos relatos históricos. E, mais fundamentalmente, desafia tanto a competência de qualquer reivindicação da história de fazer um relato completo quanto à perfeição e à presença intrínseca do objeto da história - o Homem universal. (SCOTT, 1992, p. 78)

Assim como na historiografia, houve um longo período no qual as mulheres tiveram seu direito de fala negado em outras tantas instâncias sociais. A literatura, por exemplo, é uma dessas áreas e se configura em um ambiente no qual, as que primeiro arriscaram-se a participar, escondiam-se, muitas vezes, por trás de pseudônimos masculinos e procuravam negar os possíveis traços de uma "escrita feminina”. Ana Cristina Cesar (1999), ao estudar a poesia feminina, já levantava questionamentos a respeito dessa escrita: haveria mesmo distinção entre a essência masculina de escrever e a feminina? Além disso, há diferenças entre ser uma mulher que escreve e aquela que, enquanto escritora, deixa transparecer uma áurea feminina no texto? A crítica feita anteriormente parecia perceber a existência desses traços e preferia textos nos quais eles fossem pouco visíveis. 
Com essas barreiras estabelecidas, hoje em dia, à luz dos estudos e esclarecimentos que histórica e socialmente adquirimos em relação à situação da mulher na sociedade, principalmente graças às pesquisas feministas, convém questionar: por que a escrita feminina parecia tão perigosa ao ponto de ser vedada pela sociedade? E ainda: o que querem e transmitem as mulheres com essa literatura?

Nessa linha de questionamentos, cabe conceder atenção à obra de duas autoras nordestinas que, mesmo de maneiras muito diferentes, deixaram caminhos para que pudéssemos compreender a problemática e levantar outras questões. Rachel de Queiroz, escritora cearense já consagrada na literatura brasileira, com o romance O quinze (1930), elabora uma personagem feminina com ideais subversivos fortíssimos para a produção da época. Conceição é uma moça de personalidade firme, estabelecida às próprias custas, embasada com estudos filosóficos e sociais que lhe permitem a compreensão de que tipo de sujeito ela é e, principalmente, que tipo almeja ser.

Heleusa Câmara, por sua vez, é uma autora baiana que, também buscando representar as mulheres nordestinas, constrói personagens da massa popular, sem estudo ou filosofias acadêmicas, imersas na cultura local da qual fazem parte e condicionadas pelos amores que desejam. Mulheres acorrentadas (1982) é uma coletânea de contos que espirra na cara do leitor as correntes ideológicas que encarceram mulheres interioranas todos os dias.

Tendo mulheres de ambas as obras como objeto de estudo, o objetivo desse trabalho não poderia ser outro senão o de comparar a escrita dessas duas mulheres, procurando compreender como ocorre seus processos de construção do sujeito protagonista feminino. Como é a mulher da narrativa de racheliana e como se arquitetam as de Câmara? Para pensar esses desdobramentos, sustentamo-nos na Análise Crítica do Discurso (ADC) proposta por van Dijk (2010), para que possamos, com aporte de teóricas como Virgínia Woolf (2014-13), Joan Scott (1992), Bella Jozef (1989), Ana Cristina Cesar (1999), Simone de Beauvoir (2016), bell hooks (1995), Adriana Barbosa (2011), dentre outras, analisar, como pesquisadoras, além da condição social que permeia a construção de gênero, a escrita de mulheres que escrevem sobre mulheres. 


\section{Quando as mulheres escrevem}

Recuperando a discussão proposta por Scott a respeito da universalidade do sujeito, ao passo que a escolaridade das mulheres esteve censurada, como poderiam elas inserir-se no mundo da escrita e produzir a chamada literatura universal? Como essas pessoas poderiam ser vistas como sujeitos históricos? Virgínia Woolf (2014), em Um teto todo seu, já problematizava essas questões ao perceber que para uma mulher escrever, é necessário que existam condições propícias a isso. A mulher que não pode ter independência econômica ou um espaço para chamar de "todo seu" enquanto escreve, encontra dificuldades para desenvolver sua escrita ou outras habilidades intelectuais. Woolf vai além disso e ainda cita condições históricas que privaram as mulheres de espaços como universidades, experiências fora do lar, tal qual os homens possuíam, e até mesmo o direito de expressar livremente opiniões e desejos.

A justificativa histórica para essas privações pode estar no que transmite as ideias de van Dijk (2010), uma vez que estes são elementos que se encaixam nas estratégias de dominação do poder social de um grupo sobre outro:

Quanto menos poderosa for uma pessoa menor o seu acesso às várias formas de escrita e fala. No fim das contas, os sem-poder "não têm nada para dizer", literalmente, não têm com quem falar ou precisam ficar em silêncio quando pessoas mais poderosas falam, como no caso das crianças, dos prisioneiros, dos réus e (em algumas culturas, incluindo algumas vezes a nossa) das mulheres. (VAN DIJK, 2010, p. 44)

Diante de suas limitações, o lugar de fala feminino começa tímido, acuado, restrito ao ambiente privado do próprio lar, construindo testemunhos poéticos subjetivos em cartas e diários, por exemplo (JOZEF, 1989). A escrita trazia grandes marcas de pessoalidade, assuntos relativos ao dia a dia da casa e da família, bem como alguns sutis desejos femininos.

Devido à diversidade evidente dos vários perfis de mulheres que se reconhece na sociedade, é difícil traçar características do que seria uma “escrita feminina”, porém, mesmo assim, verificou-se grandes marcas de testemunho e relatos do ambiente do lar. Houve 
também a delimitação de um estereótipo, cunhado, principalmente, pelos críticos literários que não reconheciam traços da dita "literatura universal" na escrita das mulheres, o que destinou a esta vertente definições como "escrita sentimentalista", "melosa", ou até mesmo "limitada ao impulso do sentir".

Esses estigmas contribuíram para estabelecer um lugar de inferioridade e marginalização para a escrita feminina. Falar do pessoal, do privado, era "coisa de mulher" e, portanto, fugia ao "interesse universal" do qual a literatura deveria tratar. Algumas mulheres, então, procuraram, talvez como uma estratégia de busca de reconhecimento, negar um estilo feminino de escrita e se propuseram, como temática principal, a não falar sobre o pessoal e sim sobre assuntos considerados comuns à sociedade. Rachel de Queiroz, uma das mais citadas e reconhecidas escritoras brasileiras, pode ser inicialmente colocada como um exemplo dessa condição.

\section{Rachel de Queiroz}

Com a publicação de O quinz̧e em 1930, seu primeiro romance, Rachel consagra-se como escritora ainda aos vinte anos. Recebe muitos elogios da crítica, que a louva por tratar de um tema de grande importância como a seca no Nordeste, isso dentro de uma fase do Modernismo que ganhava cada vez mais adeptos, e principalmente por não utilizar uma escrita feminina carregada de subjetividades. Rachel, permanecendo sob os holofotes da crítica, reafirma o seu lugar de escritora distante das tendências da escrita feminina e do que requisitavam as mulheres e procura assumir uma postura que faz referência à leitura de autores canônicos, em sua maioria homens.

Aqui convém mencionar um posicionamento apontado por Scott, no qual, ao falar sobre historiografia ocidental, a autora procura apontar como esta área de conhecimento posiciona a mulher. Segundo ela, “o sujeito tem sido incorporado com muito mais frequência como um homem branco, a história das mulheres inevitavelmente se confronta com o ‘dilema da diferença' [...]”' (SCOT'T, 1992, p. 77). Dessa maneira, a mulher acaba sendo o 
sujeito estranho, aquele que não é comumente visto fora da posição de objeto, isto é, mulheres não ocupam a posição de escritoras, muito menos de protagonistas ativas e transgressoras em obras literárias, e muito menos alcançam a glória de compor o cânone. Ao fazer isso, porém, instala-se a possibilidade de outros lugares de fala que não o do centro, apesar deste não-centro poder sempre ser visto como inferior e menos qualificado.

A postura assumida por Rachel, mesmo que de forma não intencional, reflete uma posição ideológica que, para não ser excluída, taxada como marginal ou privada do direito à voz, adere ao sistema de escrita patriarcal para que a partir dele possa se manifestar segundo as suas próprias necessidades. Dentre os diversos conceitos de ideologia, este trabalho assume o que propõe Van Dijk, porta voz da ACD:

[...] uma ideologia é uma estrutura cognitiva complexa que controla a formação, transformação e aplicação de outros tipos de cognição social, tais como o conhecimento, as opiniões e as posturas, e de representações sociais, como os preconceitos sociais. Essa estrutura ideológica em si consiste em normas, valores, metas e princípios socialmente relevantes que são selecionados, combinados e aplicados de forma tal a favorecer a percepção, interpretação e ação nas práticas sociais que beneficiam os interesses do grupo tomado como um todo. (VAN DIJK, 2010, p. 48)

Rachel afirma com veemência que nega feminismos e que sua escrita não cumpre com as tradicionais escritas femininas. Ao assumir essa postura, a autora concorda com um discurso ideológico hegemônico da literatura e, devido a isso, os autores da época conseguem encontrar semelhanças da obra da autora com a literatura e crítica literária produzida por eles próprios, como é possível perceber na nota de Augusto Frederico Schmidt, presente na $15^{\mathrm{a}}$ edição ${ }^{15}$ d'O quinẓ: "Nada há no livro de D. Rachel de Queiroz que lembre, nem de longe, o pernosticismo, a futilidade, a falsidade da nossa literatura feminina. É o livro de uma criatura simples, grave e forte, para quem a vida existe" (SCHMIDT, apud

\footnotetext{
${ }^{15}$ A nota de edição citada foi publicada originalmente em 1930, na primeira edição do romance O quinže. A versão presente na $15^{\mathrm{a}}$ ed. foi transcrita da $8^{\mathrm{a}}$ edição da obra de Rachel de Queiroz.
} 
QUEIROZ, 1972, p. 7). Comentários como este foram comuns em relação ao fenômeno da literatura que mostrou ser Rachel de Queiroz e até mesmo a autora faz uso desses posicionamentos.

Entretanto, mesmo havendo uma suposta negação de um estilo de escrita feminino, é possível encontrar no romance passagens que o categorizam como tal. A própria Rachel e a crítica assumiram que o texto abarca muitas experiências reais, vividas pela autora e por pessoas que presenciaram a seca nordestina, contudo, seu aspecto de experiência acaba ficando restrito, segundo a crítica da época, ao que tange à realidade devastadora da seca. Neste caso, a personagem Conceição é pouco observada, perdendo protagonismo para a realidade sofrida da família de Chico Bento. Em outras palavras, por mais que a obra apresente uma personagem feminina subversiva, engajada em leituras sociais e com posicionamentos ideológicos feministas, por parte da crítica da época, pouca atenção é dada a ela, uma vez que o assunto era pouco importante.

O discurso veiculado por Rachel de Queiroz é, em grande parte hegemônico, universal, masculino, tanto que Augusto Schmidt diz com grande excitação querer "chamar a atenção para um livro que vem revelar a existência de um grande escritor brasileiro, inteiramente desconhecido. Grande escritor que é uma mulher, incrivelmente jovem” (SCHMIDT, apud QUEIROZ, 1972, p. 6). Porém, isso não anula o fato de a obra possuir uma personagem que traz consigo ideais femininos e feministas transgressores.

Rachel traça uma estratégia literária na qual ela parece ter consciência de que só seria reconhecida como escritora, caso agisse segundo o padrão literário exigido na época, mas faz isso utilizando temas de cunho social que precisavam ser abordados, através de personagens transgressores e uma protagonista que, apesar de parecer sutil, mostra-se impactante e subversiva para a literatura brasileira.

Conceição é uma mulher adulta, jovem, com condições financeiras que lhe permitem uma vida longe dos sofrimentos da seca. É professora e está sempre mergulhada em livros com ideais de cunho social, que vão além dos limites de 1915 ou 1930. Conceição vê na possibilidade de casar-se uma limitação da mulher que ela se tornou e é por isso que 
desiste de tentar um relacionamento com Vicente, o primo por quem era apaixonada. A moça vê no jeito rude do rapaz estereótipos patriarcais com os quais não concorda e, além disso, seu distanciamento da vida acadêmica também se torna um ponto fundamental para que seja estabelecida, para Conceição, uma grande diferença entre eles:

Foi então que se lembrou de que, provavelmente, Vicente nunca lera o Machado... Nem nada do que ela lia.

Êle dizia sempre que, de livros, só o da nota do gado...

Num relêvo mais forte, tão forte quanto nunca o sentira, foi-lhe aparecendo a diferença que havia entre ambos, de gôsto, de tendências, de vida. (QUEIROZ, 1972, p. 84)

Conceição escolhe não insistir em seu amor por Vicente, pois acha que não estão no mesmo nível. Sente que a presença de um homem pode fazê-la voltar atrás em relação a tudo que é e tudo que já estudou ou leu. Além disso, o maior diferencial de Conceição em relação às regras do sistema patriarcal impostas às mulheres é o fato dela não querer se casar ou ser mãe: "Conceição tinha vinte e dois anos e não falava em casar. As suas poucas tentativas de namoro tinham-se ido embora com os dezoito anos e o tempo de normalista; dizia alegremente que nascera solteirona" (QUEIROZ, 1972, p. 31). Convém ainda lembrar que este discurso, se já é subversivo nos dias de hoje, nos anos 30 deve ter ocasionado um grande impacto e surpresa no público leitor.

Apesar disso, é provável que os críticos mais influentes do período de publicação da obra ainda não soubessem ou não suspeitassem da importância que Conceição e a própria Rachel viriam a ter para a literatura e os estudos da crítica feminista. Durante muito tempo, a autora foi lida por olhos masculinos, no intuito de que não fossem transmitidas feminilidades, porém, Rachel consegue de maneira sutil e astuciosa implantar a sua ótica feminina.

Segundo Andréa Padro (2019), em sua dissertação de mestrado na qual escreve sobre feminismo, escrevivência e autoficção em Rachel de Queiroz, a escritora traçou como estratégia para ser notada e aceita pela crítica, fazer uso de uma "escrita masculina". Para Prado, Rachel “Também fez concessões; abriu mão de ser associada a uma voz feminina; 
escreveu, segundo críticos, como homem, ao menos inicialmente, mormente em O quinze" (PRADO, 2019, p. 48). Percebe-se aqui um envolvimento com o discurso de negação, sendo favorável ao poder social vivente, com o objetivo de não ser associada a uma voz subalternizada. Além da primazia de sua obra, esse pode ter sido um fator importante para apresentar Rachel de Queiroz ao cenário literário e até mesmo para incutir em seu discurso pessoal uma distância em relação ao movimento de mulheres, uma vez que ser contra o discurso dos grandes críticos significava não ter oportunidade de fazer literatura.

Hoje surge uma nova maneira de ler Rachel de Queiroz, observando-a como mulher escritora, que dá voz a mulheres marcantes, como ela mesma o fora. Rachel, lida e analisada por mulheres, revela um universo antes pouco percebido e explorado, apresentando um discurso que que gira em torno da emancipação feminina.

Vê-se, portanto, que em alguns casos é necessário que o objeto seja visto na posição de sujeito para que se possa alcançar uma análise mais profunda. Os críticos de Rachel deram atenção à sua linguagem precisa para falar do regionalismo, porém, talvez pelo fato de pensarem de forma falocêntrica, pouco observaram o que havia de inovador e provocativo na personagem Conceição. Às vezes, um observador específico é capaz de enxergar aspectos que outros não alcançariam, isto é, como questionou Scott, "qual o relacionamento entre o historiador e os sujeitos sobre os quais ele/ela escreve?" (SCOTT, 1992, p. 78). Como bem indagou Virgínia Woolf (2013) na resenha A nota feminina na literatura, o melhor crítico para um texto feminino não seria uma outra mulher? A pergunta de Woolf nos leva a pensar que a produção feminina, por ser tão inovadora, contendo a marca da diferença em relação à concepção universal, isto é, masculina, carrega marcas de experiência e testemunho que desperte empatia e autorreconhecimento em outras mulheres.

\section{Heleusa Câmara}

$\mathrm{O}$ motivo que condiciona pesquisadores e pesquisadoras a estudar determinado tema normalmente está ligado a algum âmbito pessoal e subjetivo, assim, feministas são condicionadas a estudar a história das mulheres ou a Crítica Feminista, por exemplo, bem 
como escritoras podem sentir a necessidade de escrever sobre a realidade feminina, seja esta a sua própria ou de outras mulheres à sua volta.

A esse paradigma também se encaixa Heleusa Figueira Câmara, escritora baiana, natural da cidade de Vitória da Conquista, que, assim como Rachel, procurou não levantar bandeiras referentes ao feminismo, mas transmite em sua escrita mulheres fortes e subversivas que podem ser analisadas a partir da Crítica Feminista. Mulheres acorrentadas (1982), obra publicada 52 anos depois d'O quinze, trata-se de um livro de contos no qual as protagonistas são sempre mulheres, em sua maioria comuns, interioranas e com pouco ou nenhum dinheiro. Mulheres que vivem de acordo com o sistema patriarcal vigente, mas que de alguma forma rompem com um outro padrão falocêntrico. Trata-se de uma obra que mostra o feminino acorrentado, como bem diz o título, mas que também quebra, burla ou subverte essas correntes. Como é possível notar na orelha do livro, escrita pelos editores:

Seu universo ficcional é criado a partir de um pequeno e estreito universo de uma cidade do interior, mas amplo pela universalidade dos tipos humanos, onde dominam ainda os hábitos e costumes patriarcais, sendo a mulher, por herança, o objeto de posse, e por mais que se queira libertar para adquirir sua individualidade, estará sempre acorrentada por preconceitos que agem com força imponderável. (CÂMARA, 1982)

A proposta da autora se concentra, portanto, em apresentar ao leitor uma diversidade de mulheres comuns, isto é, a "universalidade de tipos humanos" que, ao chamarmos de "humanos", parece não carregar a marca de gênero, cuja reivindicação é frequente nas denúncias feministas em torno da misoginia, machismo e sexismo, é justamente uma tentativa de chamar atenção para a vastidão de mulheres que há. Porém, aqui entendo que, ao dizer "universalidade de tipos humanos", procura-se falar, na verdade, na posição de sujeito que as personagens possuem na obra e que deveriam ter na vida real, posição esta que não possui nenhuma relação com o universalismo proposto pelo cânone e pela ideologia patriarcal.

Escrever, no ano de 1982, que se procura abordar sobre uma universalidade de tipos de mulheres não parece ser outra coisa senão retirar da posição de objeto, tornar sujeito e 
dar voz às mulheres que, também pela condição social, nunca foram vistas de tal forma pelo sistema vigente.

Tanto o discurso percebido em Rachel de Queiroz quanto em Câmara, refletem a necessidade de conceder voz e protagonismo às mulheres. Rachel realiza isso de forma mais sutil a partir do momento em que emparelha à personagem Conceição a família de Chico Bento. Isso faz com que, para quem olha de acordo com a perspectiva patriarcal, a realidade de Chico Bento passe a ser mais impactante, e, portanto, chame mais a atenção do leitor, do que a de Conceição. O protesto realizado através de Conceição é discreto, percebido muito mais pela crítica feminista atual do que pela crítica literária, dita universal, de outrora. Já a escrita de Câmara nos apresenta a um discurso mais direto, uma vez que deixa esclarecido a quem pertence o protagonismo da obra e que há uma forma de pensar a sociedade que precisa ser revista.

Outro diferencial da escrita de Câmara em relação à de Rachel é a mudança do protagonismo de classe social. A maior parte dos contos da obra são protagonizados por mulheres pobres e não se pode deixar de notar que, ao mudar o foco da vida de uma personagem que ocupa a posição da patroa (Conceição), para a empregada doméstica que está nos contos de Câmara, há também uma mudança no sentido de chamar de sujeito um outro grupo ainda mais silenciado no decorrer da história. A literatura de Câmara abrange mulheres colonizadas, negras, com baixa escolaridade, mulheres que nunca se viram capazes de ascender na vida e pensam que isso apenas poderia ocorrer através de um marido e/ou marido rico.

Pensadora negra contemporânea, bell hooks ${ }^{16}$ apresenta-nos, no artigo Intelectuais negras, à realidade das mulheres negras em relação ao pensamento intelectual. Para ela essas mulheres não são culturalmente estimuladas a estar nessa posição. Há barreiras relacionadas à condição de classe, ao acesso à escolarização, às responsabilidades da vida em família, à

${ }^{16}$ Por uma questão de autoidentificação a autora prefere que seu nome seja escrito em minúsculo. 
posição de mãe, principalmente a mãe solo, além do próprio racismo e sexismo que enfrentam. Ao falar do contexto capitalista, no qual a maioria das pessoas intelectuais é branca e masculina, hooks afirma que as mulheres negras precisam assumir um pensamento descolonizado para almejarem conquistas bem-sucedidas. Rachel de Queiroz, talvez pela classe que representa, consegue criar uma protagonista que se liberta desse pensamento. Por compreender essa importância, Conceição desprende-se do estereótipo do amor romântico, aquele com o qual, culturalmente, toda mulher deve sonhar e tudo suportar, ao passo que as mulheres de Câmara ainda demonstram um pensamento subserviente, no qual o encontro com o amor as coloca em situação de sonho almejado e também de dependência do homem amado, deixando transparecer o anseio por alguém que comande suas vidas.

Câmara escreve sobre mulheres que estão longe de pensar da maneira subversiva de Conceição, mulheres que não levantam um discurso político e socialmente engajado em discussões pertinentes ao mundo letrado, politizado ou branco. As mulheres de Câmara são aquelas que poderiam ser categorizadas como "mulheres da massa popular", que não são intelectuais, que não problematizam ou refletem a respeito do seu lugar de fala ou posição que ocupam no mundo de classe. Contudo, isso não quer dizer que elas sejam mulheres que não protestam contra o sistema patriarcal. A subversão que demonstram parte de suas ações, de sua maneira de se relacionar com as determinações de gênero tradicionais e a forma como estão ou deixam de estar reféns do homem amado. Ou seja, a revolução que estas mulheres representam acontece no ambiente privado do lar.

Como dito anteriormente, escrever sobre o pessoal e o privado foi algo taxado como característico da escrita feminina. Rachel abordou este tema, porém ainda tentou direcionar grande parte da trama de O quinze para a família de Chico Bento, pois talvez assim pudesse ser mais valorizada enquanto escritora. A respeito disso nos fala Adriana Barbosa:

Em literatura, a autoria feminina (bem mais do que a masculina) tem percorrido o território doméstico. Desse modo, desde os primeiros passos, a literatura feminina esteve associada as temáticas do cotidiano, da intimidade e do doméstico sob uma estética intimista e confessional. E justamente por isso fora considerada menor: por tratar 
de trivialidades, amenidades e assuntos menos sérios, numa época em que o mundo privado era estigmatizado e, junto com ele, sua protagonista: a mulher. Com medo da caracterização de literatura menor, muitas das autoras brasileiras não reconhecem em suas obras nada que possa ser associado a uma suposta linhagem do feminino. (BARBOSA, 2011, p. 76)

Câmara, tal como Rachel, apesar de também trazer representações regionais da vida quase sempre pobre no interior da Bahia, mantém como foco de suas narrativas as particularidades de cada mulher que protagoniza seus contos, estando elas quase sempre no ambiente privado e lidando, principalmente, com conflitos amorosos. A autora produz uma literatura gendrada, admitindo que seu objetivo é falar a respeito da condição da mulher interiorana, fisgada pela cultura patriarcal e falocêntrica, apresentando um sujeito que é atravessado e indissociável da cultura que o construiu.

Lívia Natália Santos (2018), ao discutir sobre a representação da voz e posição de sujeitos subalternizados negros na literatura, principalmente em relação às mulheres negras, expõe contrapontos em relação à dualidade sujeito hegemônico versus não sujeito. Segundo a autora,

A ilusão de abarcar a totalidade que atravessou todas as ciências, instaurou um corte profundo na Teoria da Literatura através da deliberada crença, ainda Moderna, de que ou haveria a alta literatura ou literatura nenhuma. Neste ínterim, a formação dos critérios de seleção e atribuição de valor literário concentrou-se na valoração estética como se este fosse um padrão isento de juízo de valor. Não é impossível que esta forma de compreender a literatura tenha sido engendrada por uma ilusão de que o discurso literário, sublime que é, estaria fora do poder. (SANTOS, 2018, p. 2)

Santos confirma que as relações de poder permeiam a literatura. Tal poder social vai desde a escolha estilística e estética do que seria a literatura de qualidade, até a construção de personagens e enredos. Diante disso, grupos subalternos como mulheres negras, brancas e/ou pobres, homens negros e pessoas LGBT sempre viveram sob silenciamento histórico.

Não obstante, se a mulher ao longo da historiografia e de grande parte da produção literária, até mesmo de algumas produções femininas, ocupou o lugar de "sujeito histórico 
adicional" (SCOTT, 1992, p. 81), é na escrita engajada feminina, tal como a de Heleusa Câmara, que se percebe uma ânsia em denunciar a posição subalternizada das mulheres enquanto sujeitos e agentes da subversão. Câmara propõe mulheres fortes e ativas que depois de sofrerem decepções e serem colocadas em lugar de inferioridade pelos próprios parceiros, conseguem quebrar ciclos de abusos e tornam-se norteadoras do próprio destino, tal como Joana e Loura, protagonistas dos contos Joana da cata-nica e As lutas de Loura, respectivamente.

Joana é uma jovem negra, empregada doméstica, que trabalha e mora no quartinho dos fundos da casa de uma família de classe média. Desejosa de aproveitar melhor seus dias e tempo livre após o trabalho, começa a passear todos os dias em uma cata-nica, da qual Edvaldo, homem branco e pai de família, é o motorista. Os dois envolvem-se amorosamente sem que Joana soubesse que o moço era casado. Edvaldo escolhe, por fim, continuar com a esposa, devido à casa que ela ganhara do pai, e dispensa Joana que, após esfaquear Edvaldo movida pelo ódio da recusa amorosa, descobre estar grávida dele. A jovem esconde a gravidez de todos, induz a morte do feto com cintas que comprimem o abdome, dá à luz sozinha a uma criança natimorta, atira-a na cisterna da casa de Edvaldo como forma de vingança, pega todas as economias que juntou ao longo do seu trabalho e vai embora para São Paulo tentar uma nova vida.

Já Loura, após realizar o sonho do casamento ao lado de Pedro, depois do nascimento do primeiro filho, começa a emagrecer e deixa de ser atraente aos olhos do esposo que sempre preferiu mulheres gordas. Pedro envolve-se com muitas outras mulheres e a vida de Loura passa a ser a de perseguir e espancar essas mulheres. Com o tempo, Pedro morre assassinado pelo marido de uma de suas amantes e Loura, mesmo contra vontade, casa-se novamente com Vavá, homem rude e possessivo, suspeito de matar sua primeira esposa. Vavá espanca Loura sempre que está bêbado até que um dia, quando ela reage a uma de suas surras, é intimidado e baleado pela mulher, que difere disparos contra ele e contra a casa. A partir de então Vavá vive acuado, com medo de Loura, até que foge de 
vez, desaparecendo sem deixar rastros, deixando Loura ainda apaixonada e na dependência afetiva que sentia por Pedro, seu primeiro marido.

Retorno à Scott com uma citação que julgo pertinente para entender um pouco do que representa a escolha de Câmara em posicionar essas duas mulheres como personagens marcantes de sua obra:

[...] pensando em termos da lógica contraditória do suplemento, podemos analisar a ambiguidade da história das mulheres e sua força política potencialmente crítica, uma força que desafia e desestabiliza as premissas disciplinares estabelecidas, mas sem oferecer uma síntese ou uma resolução fácil. O desconforto subjacente a tal desestabilização conduziu não apenas à resistência por parte dos historiadores "tradicionais", mas também a um desejo de resolução, por parte dos historiadores das mulheres. Entretanto, não há resolução simples, mas apenas a possibilidade de constante atenção aos contextos e significados no interior dos quais são formuladas as estratégias políticas subversivas. (SCOTT, 1992, p. 76-77)

Contextualizando o argumento de Scott à escrita de Câmara, percebo que a autora realmente cumpre o que prometera, apresentando narrativas que não parecem estar atreladas a feminismos. Percebo, por exemplo, em Loura uma falta de sororidade latente, uma vez que para ela a culpa da infidelidade do seu marido não está no caráter ou personalidade dele e sim nas outras mulheres, as quais parecem ser responsáveis por desvia-lo do seu caminho como homem que honra o casamento. Loura concentra seu ódio nas outras mulheres e não nas traições de Pedro, bem como Joana ao achar que Edvaldo e ela seriam felizes se não fosse pela interferência da esposa dele. Além disso, ambas as mulheres apenas saem da situação de submissão econômica e afetiva porque foram decepcionadas e obrigadas a fazê-lo, caso contrário, continuariam com os homens que as subjugavam, reproduzindo e sendo vítimas do pensamento patriarcal que as oprimia.

Simone de Beauvoir (2016), já alertava, ao falar sobre a mulher independe, a respeito das amarras que encarceravam desde a cortesã, até a esposa. Para a filósofa francesa, as duas dependem e estão igualmente subjugadas ao homem. Ser a esposa amada por exemplo, sonho desejado por Joana e Loura, acaba delegando à mulher limitações atreladas à 
dependência econômica, uma vez que, na sociedade de outrora, as mulheres eram sustentadas por seus maridos, e à dependência emocional causada pela ideia de amor romântico, ao qual a dedicação feminina parece ser primordial ao sucesso do casamento.

Diante disso, como afirmou Scott, não se pode esperar uma "resolução simples", completamente enraizada em feminismos, uma vez que o contexto sócio histórico e o discurso que interpela essas mulheres não abrangem essas discussões. A escrita de Câmara é interpelada por aquele discurso vigente e aqui, devido, talvez, à falta de letramento das personagens em questão, não há meio para surgimento de discussões intelectuais, filosóficas ou sociais como as que são feitas por Conceição em O quinそe. A subversão proposta por essas personagens está em suas ações, realizadas como último recurso de salvamento próprio, as quais, carregadas de violências, tal qual o fato de Joana ter esfaqueado Edvaldo e Loura ter atirado em Vavá, são responsáveis por permitir às mulheres uma nova condição de existência.

Van Dijk (2010), ao falar sobre as estruturas do discurso e estruturas do poder, estuda algumas relações entre discurso e o efeito que ele causa ao poder social. São apresentadas oito principais características do poder social, as quais, resumidamente, se constroem nas relações entre grupos e classes sociais, manifestando-se através dessa interação, ocasionando a manipulação e dominação de um grupo sobre outro e ditando suas crenças, desejo e cultura. Esse poder social não se trata de algo visível ou palpável, ele se propaga através do imaginário coletivo, se configurando em uma forma de controle social. Entretanto, o grupo subjugado aos efeitos desse poder pode desenvolver estratégias de resistência, um contrapoder que assume uma postura argumentativa de contradiscurso, que resiste à estrutura ideológica regente.

A literatura de autoria feminina pode ser encarada como esse contradiscurso, utilizado para veicular, legitimar e chamar novos sujeitos para serem agentes subversivos em um contrapoder que se propõe a questionar o sistema patriarcal e falocêntrico, observado durante tanto tempo como universal e abrangente, uma vez que se acostumou a ser analisado por olhos que estavam de acordo às suas ideologias. Tanto a Crítica Feminista como 
a literatura produzida por mulheres são maneiras diferentes de olhar um centro hegemônico estabelecido ao longo da história.

Ao promover essa subversão, entretanto, não se pode esperar que ela ocorra de maneira direta e imediata, na intenção de afrontar e ver-se livre do patriarcalismo. Ainda nesse contradiscurso observa-se a presença e interpelação da cultura que molda a sociedade brasileira nordestina, uma vez que Rachel de Queiroz, mesmo criando uma personagem que subverte os padrões esperados para a mulher branca de classe média dos anos 1930, ainda o faz em uma escrita camuflada de "escrita masculina", longe dos "sentimentalismos da literatura feminina". Talvez as leituras anteriores de Rachel tenham inspirado a escritora que ela se tornou, talvez a recusa da crítica em relação às mulheres escritoras também tenha contribuído para a construção do seu estilo, enfim, podem ser diversos os motivos que fizeram com que a escrita de Rachel caminhasse para um patamar de "escrita masculina".

Finalmente, em Câmara observa-se que as interpelações do sistema e discurso hegemônico se encontram na pretensão de vida, de acordo com este sistema que as personagens tanto almejavam. Aqui o contradiscurso surge não por vontade própria das protagonistas, tal como ocorre com Conceição, mas elas são obrigadas pelas circunstancias a buscarem caminhos de ruptura, quebrando os limites do amor romântico, que as obrigam a seguir a vida sem a figura masculina. Conceição, ao contrário, entende que seria melhor para si não se relacionar com o homem que ama devido às possíveis limitações que ele lhe ofereceria, tratando-se, portanto, de uma escolha consciente.

\section{Conclusão}

O que se percebe é que a literatura das autoras analisadas caminha para o mesmo destino, mesmo que de maneiras diferentes. Ambas trabalham com as correntes que aprisionam as mulheres na sociedade brasileira de cada época e propõem meios para que essas mulheres burlem esse sistema, o qual não parece reconhecê-las com sujeito histórico social. A postura de escrita das autoras é diferente, mas ainda assim, parecem acreditar que levantar uma bandeira feminista pode limitá-las de alguma forma. 
Ainda hoje é interessante pensar o que há no feminismo que divide tanto a sociedade, que parece ocasionar tanta recusa e rejeição e quem seria o sujeito mais interessado nessa recusa. No começo desse texto questionei o motivo pelo qual a escrita feminina parecia tão perigosa aos intelectuais de outrora e o que querem as autoras com essa literatura. É possível existir ou não respostas para estas indagações, porém, para começo de reflexão, convém pensar na desordem que se instalaria/instalou no patriarcalismo depois que as mulheres reivindicarem/reivindicaram sua posição de sujeito.

Ser reconhecida como mulher escritora vai além de fazer literatura, sendo também uma forma de contestar o discurso vigente, camuflado de universal, mas, quando visto por quem não faz parte do grupo que o constitui, possui a face de um homem branco, heteronormativo e com poder de classe. O contradiscurso e contrapoder da escrita feminina costuma reivindicar reconhecimento social baseado na diferença, mas, sobretudo, reivindica que falemos por nós mesmas. Afinal, como afirmou Beauvoir: "Mesmo falando de temas gerais, a mulher que escreve ainda falará de si [...]" (BEAUVOIR, 2016, p. 531).

A escrita dessas duas autoras, à guisa de conclusão, representa o poder discursivo que interpela as mulheres nordestinas, apresenta sua diversidade de classe, escolaridade, raça, maneira de ser/estar no mundo, além da forma como encaram o amor romântico. Preliminarmente, trata-se de reivindicar-se como sujeito histórico social, portador voz autônoma, diretos e denúncias, e até mesmo a permissão para dizer-se existente em meio a um discurso hegemônico que nunca antes lhes havia concedido protagonismo. 


\title{
FEMALE WRITING AND SPEECH: \\ THE DISCOVERY OF A SUBJECT IN RACHEL DE QUEIROZ AND HELEUSA CÂMARA
}

\begin{abstract}
The present work proposes to read and analyze the writing and the feminine speech in the northeastern writers Rachel de Queiroz and Heleusa Câmara, in order to problematize the discovery and construction of the feminine subject. The object of study is Rachel de Queiroz's first novel, O quinze, first published in 1930, and thecollection of short stories by Heleusa Câmara, Mulheres acorrentadas, published in 1982, which will specifically analyze the tales Joana da cata-nica and As lutas de Loura. The objective is to problematize, through the observance of the narratives, how the construction of the female subject is performed by each author, besides questioning the notion of "universal subject". Therefore, we observe the relevance of the work, which seeks to perceive, according to the view of an element that has often been left out of history, the notion of the construction of protagonism of marginalized female subject. As a methodology, we rely on the Critical Discourse Analysis (CDA) proposed by Teun A. van Dijk (2010), in addition to pointing out the narrative discourses of the authors and their protagonists, also analyzing, from a critical-feminist perspective, how the construction of these subjects occurs.
\end{abstract}

KEYWORD: Speech; Heleusa Câmara; Woman; Rachel de Queiroz; Subject.

\section{REFERÊNCIAS}

BARBOSA, Adriana Maria de Abreu. Ficções do feminino. Vitória da Conquista: Edições Uesb, 2011.

BEAUVOIR, Simone de. O segundo sexo: A experiência vivida. $3^{\mathrm{a}}$ ed. Rio de Janeiro: Nova Fronteira, 2016.

CÂMARA, Heleusa Figueira. Mulheres acorrentadas. Rio de Janeiro: Cátedra, 1982.

CESAR, Ana Cristina. Escritos no Rio. In: Crítica e tradução. São Paulo: Ática, 1999.

HOOKS, bell. Intelectuais negras. Revista estudos feministas, v. 3, n. 2, p. 464 - 478, 1995.

JOZEF, Bella Karacuchansky. A mulher e o processo criador: A máscara e o enigma. In: COELHO, Nelly Novaes. Feminino singular: a participação da mulher na literatura brasileira contemporânea. São Paulo: Edições GRD, 1989.

PRADO, Andréa Andrade Oliveira. Escrita feminina em Rachel de Queiroz: Feminismo, autoficção e escrevivência em Dôra, Doralina e Memorial de Maria Moura. 102 fls. 2019. Dissertação (mestrado). Universidade Estadual do Sudoeste da Bahia, Programa de Pós-Graduação em Letras: Cultura, Educação e Linguagens, Vitória da Conquista, 2019.

QUEIROZ, Rachel de. O quinze. 15a ed. Rio de Janeiro: Editora José Olypio, 1972. 
SANTOS, Lívia Maria Natália de Souza. Poéticas da diferença: a representação de si na lírica afro-feminina. Literafro. Faculdade de Letras da UFMG, 2018. Disponível em:

http:/ / www.letras.ufmg.br/literafro/artigos/artigos-teorico-conceituais/154-livia-marianatalia-de-souza-santos-poeticas-da-diferenca Acesso em: 7 de jun. 2019.

SCOTT, Joan. História das Mulheres. In: BURKE, Peter (org.) A escrita da história: novas perspectivas. $2^{a}$ ed. São Paulo: Editora Unesp, 1992.

VAN DIJK, Teun A. Discurso e Poder. $2^{\mathrm{a}}$ ed. São Paulo: Contexto, 2010.

WOOLF, Virgínia. A nota feminina na literatura. In: Profissões para mulheres e outros artigos feministas. Porto Alegre: L\&PM Editores, 2013.

WOOLF, Virgínia. Um teto todo seu. São Paulo: Tordesilhas, 2014.

Recebido em: 07/08/2019. Aprovado em: 14/10/2019. 